\title{
Feasibility of Geothermal Heat Exchanger Pile-Based Bridge Deck Snow Melting System: A Simulation Based Analysis
}

\author{
Chanjuan $\operatorname{Han}^{1}$, Xiong (Bill) $\mathrm{Yu}^{2 *}$ \\ ${ }^{1}$ Ph.D. Candidate, Department of Civil Engineering, Case Western Reserve University, 10900 Euclid \\ Avenue, Bingham Building-Room 203B, Cleveland, OH 44106, cxh432@ case.edu. \\ ${ }^{2 *}$ Honorary Visiting Professor, School of Civil Engineering, Hubei University of Technology; \\ Professor, Department of Civil Engineering, Case Western Reserve University, 10900 Euclid Avenue, \\ Bingham Building-Room 206, Cleveland, OH 44106, xxy21@ case.edu, Corresponding author.
}

\begin{abstract}
Snow melting system based on geothermal heat exchanger pile is an innovative technology that combines geothermal energy with structural foundation. It overcomes the problems of conventional chemical based snow melting in mitigating infrastructure corrosion and negative environmental effects. By integrating the underground heat exchanger into pile foundation that support the bridge structure, it effectively reduces the installation cost of geothermal system. This paper analyses the applicability and performance of such snow melting system for different regions. Energy demand for snow removal is firstly determined with ASHRAE criteria. A holistic 3D simulation model is developed to predict the energy extraction rate under different operation conditions. A hypothetical bridge deck $(200 \mathrm{~m}$ length by $14.8 \mathrm{~m}$ (4 lanes) width) is analyzed to assess the feasibility of geothermal heat exchanger pile based snow melting system for 10 cities representing a variety of climatic regions of the United States. The number of pile foundation required for snow melting is used as indication of the technical feasibility. The results show that its feasibility and performance in bridge deck snow removal is dependent upon the geological and snow conditions of a particular region, as well as the design snow removal criteria.
\end{abstract}


Key words: Geothermal Heat Exchanger Pile, Snow and Ice Removal, Geothermal Heat Pump, Pile Foundation, Finite Element Simulation

\section{INTRODUCTION}

Over $70 \%$ of United State territory is located in areas with snow fall [1]. Snow can cause serious issues affecting the safety, mobility, and productivity of the transportation system [1]. According to the Federal Highway Administration (FHWA), during 2002 to 2012, around 5,878,000 annual vehicle crashes occurred on the road, $23 \%$ of which are weather-related [1]. Each year, more than 1,300 people are killed and over 116,800 people get injured in vehicle crashes on snowy, slushy or icy pavement [1]. In addition, snow incurs significant road winter maintenance cost [1]. Over 2.3 billion dollars are spent on the snow and ice removal annually, which account for $20 \%$ of state Department of Transportation (DOT) winter road maintenance budgets [2].

The prevalent method for snow and ice removal is mechanical plowing together with spraying deicing salt. This method, however, is associated with extensive transportation infrastructure corrosion, huge amount of material consumption, and negative environmental impacts. To resolve these issues, alternative methods for deicing have been proposed, such as different pavement heating techniques that use hydronic system, electric heater system or infrared radiant heating system to melt the snow and prevent pavement from freezing [3]. In 1999, FHWA reported the implementation and performance of 10 pilots projects in the United States involving the application of different heating techniques for bridge deck snow melting; these projects demonstrated positive performance for the control of snow accumulation on bridge decks [4]. Other similar projects have also been reported in Switzerland [5, 6], Japan [7-10], Germany [11], Portland [12], China [13] and Korea [14]. The hydronic system, which employs fluid to extract the natural heat from the ground, is among the most popular types of heat based snow and ice removal methods as it utilizes heat source that is widely available. It is also advantageous over the fossil fuels based heating system in terms of low environment footprint during operation. The hydronic system typically involves installing hydronic heat exchangers in the pavement. It integrates sustainable geothermal energy as the heat source. The geothermal snow melting system in Switzerland, which is part of the Solar Energy Recovery from Road Surfaces (SERSO) pilot plants, is among the most well-known geothermal snow melting systems. The system started working since 1994 and is still in service currently [5, 11]. Yoshitake et al. [7], developed an innovative geothermal snow melting system 
that directly used the heat from water stored in an underground water tank as the heat source. Spitler and Ramamoorthy [15] presented a comprehensive design procedure for a geothermal bridge deck de-icing system using TRNSYS and HVACSim + based system simulation model. Various numerical models have been developed to simulate the heat transfer of pavement snow melting process aiming at optimizing the pavement surface heating system design [15-21].

The application of geothermal heating technique is primarily for hotspot locations (i.e., bridge, airports, and hospital emergency entrances, etc.) due to its high initial installation cost, a major portion is for ground drilling and installation. The development of geothermal energy foundation, which incorporates the heat exchanger pipe into deep foundation, provides an appealing solution to save the expensive investment associated with borehole drilling. Geothermal energy pile is estimated to save up to $33 \%$ of installation cost for geothermal heat exchanger (GHE) [22]. The concept of geothermal energy pile based snow-melting system was proposed in 1990s [23]. It has received significant attention ever since, mostly concentrated on the system performance evaluation. Nagai et al. [10] reported a successful application of geothermal heat exchanger pile based snow melting system in Japan for parking lots and bridge with deck area of $1820 \mathrm{~m}^{2}$. The study also proposed the optimal design through a verified numerical model. Brower and Olgun [24] described an experimental study on energy pile based passive bridge-deck deicing system. The testbed includes a $2.4 \mathrm{~m} \times 3.0 \mathrm{~m}$ bridge deck with half of it heated by geothermal heating system (consisting of four piles each of around $30.5 \mathrm{~m}$ length). The results demonstrated the effectiveness of energy pile based geothermal snow melting system. An important issue identified is summer heat recharge. Dupary et al. [25] numerically analyzed the mechanical response of geothermal heat exchanger pile based on the prototypes of SERSO and Shin-Kiyonage bridge projects.

In this paper, computational model assisted analyses are carried out to investigate the feasibility of geothermal heat exchanger pile based snow melting system for bridge decks. Ten cities located in different climatic regions across the United States are selected for the analyses (Fig. 1(a)). These selected cities spread across 10 different states with the undisturbed ground temperature ranging from $8{ }^{\circ} \mathrm{C}\left(46.4^{\circ} \mathrm{F}\right)$ to $18^{\circ} \mathrm{C}\left(64.4^{\circ} \mathrm{F}\right)$ (Fig. 1(b)) and snowfall ranging from 13 to 224 hour/year. The computational model is used to evaluate the influence of types of heat exchanger pipe and ground heat exchanger (GHE) operational conditions (i.e., fluid circulation velocity) on the performance of GHE installed in pile foundation. The number of piles required to achieve desired snow and ice melting performance is used as criteria to evaluate the feasibility of geothermal heat exchanger pipe based snow melting system in the selected cities. 
(a)

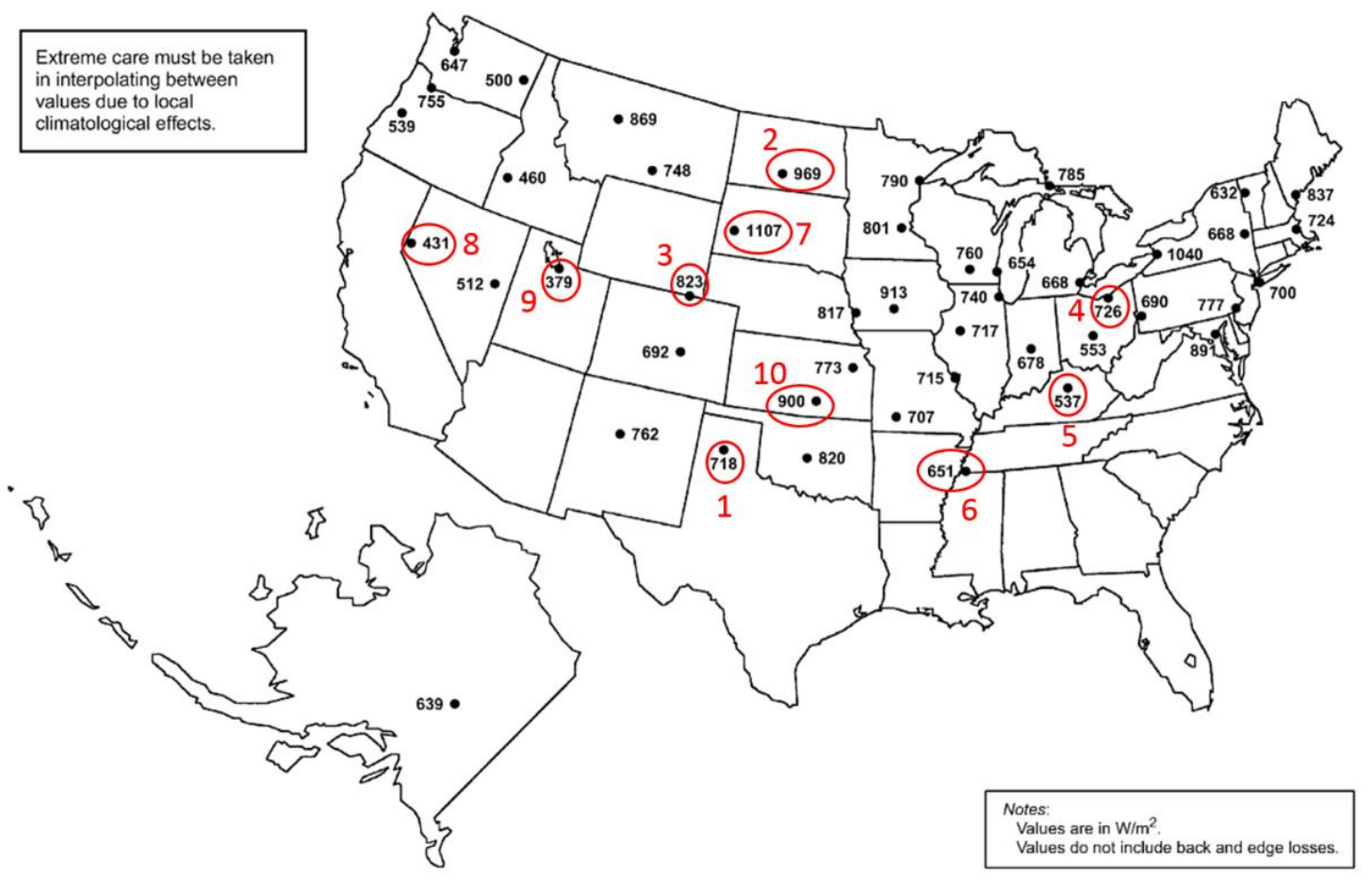

(b)

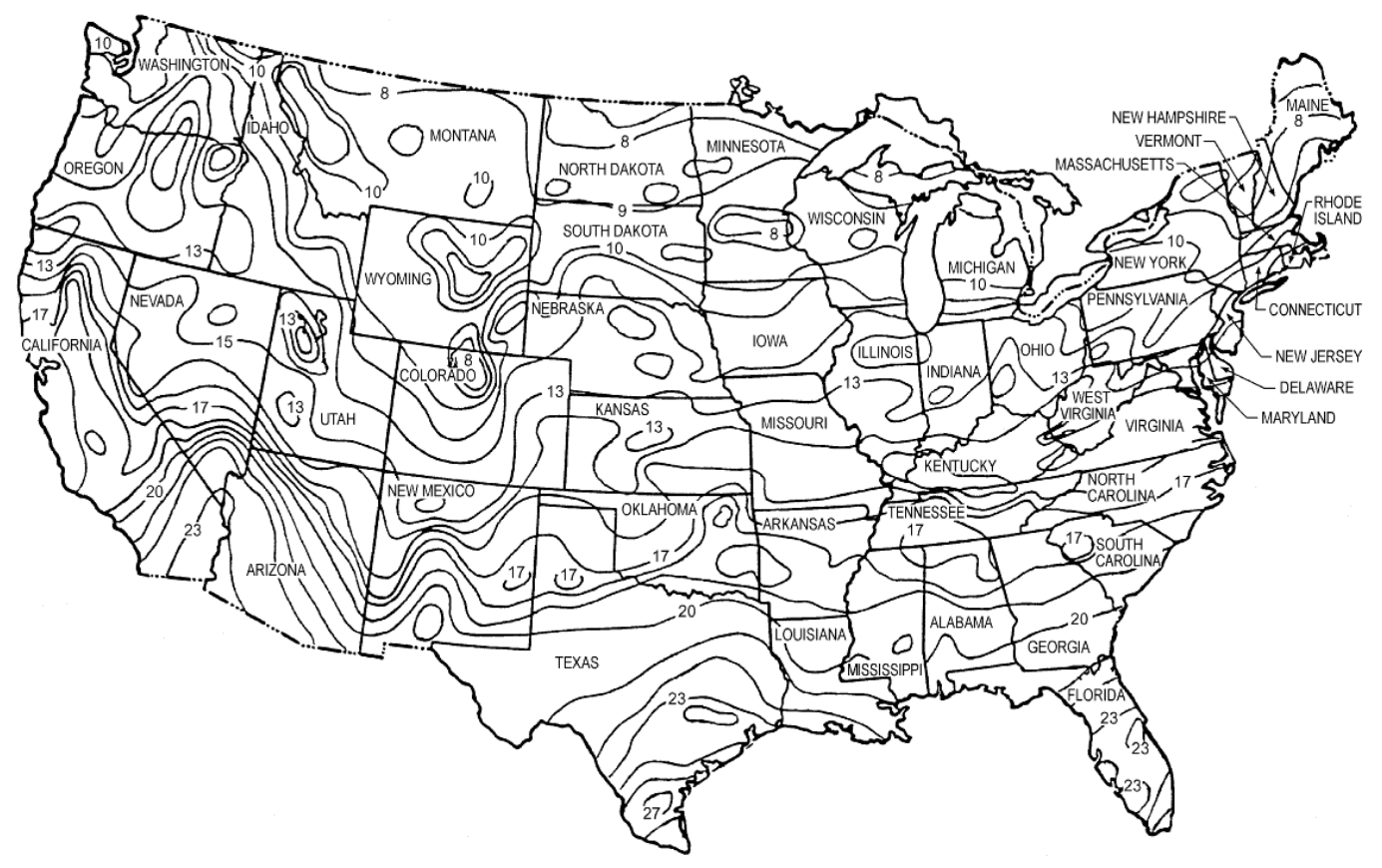

Fig. 1. (a) Snow melting surface heat fluxes required to provide snow-free area ratio of 1.0 for $99 \%$ (Note: locations of the 10 cities selected in this study are marked); (b) Approximate groundwater temperature $\left({ }^{\circ} \mathrm{C}\right)$ in the continental United States (Source: 2007 ASHRAE Handbook-HVAC Application [3]) 


\section{GEOTHERMAL HEAT EXCHANGER PILES BASED SNOW MELTING SYSTEM}

Geothermal heat exchanger pile based snow melting system generally includes four main components, i.e., 1) Pavement surface heating system; 2) Heat pump; 3) Geothermal heat-exchanger piles; and 4) System controllers and sensors. The analyses in this paper are primarily based on heat exchange aspect.

\section{Pavement surface heating system}

The pavement surface heating system consists of the hydraulic heat exchanger pipe installed beneath the pavement surface (Fig. 2). The determination of heating requirement for snow/ice removal, which is normally described by surface heat flux, provides important design capacity of the whole system. According to ASHRAE Handbook 2007, the heating requirement for snow melting are determined by five atmospheric parameters: air dry-bulb temperature, rate of snow fall, relative humidity, wind velocity and apparent sky temperature [3]. The required heat flux for snow melting on the basis of steady-state energy balance is given by [26]:

$$
q_{0}=q_{s}+q_{m}+A_{r}\left(q_{h}+q_{e}\right)
$$

where, $q_{0}$ denotes to heat flux required at snow melting surface, $\mathrm{W} / \mathrm{m}^{2} . q_{s}$ is sensible heat flux, $\mathrm{W} / \mathrm{m}^{2} . q_{m}$ represents latent heat flux, $\mathrm{W} / \mathrm{m}^{2} . q_{h}$ is convective and radiative heat flux from snow-free surface, $\mathrm{W} / \mathrm{m}^{2}$. $q_{e}$ denotes to heat flux of evaporation, $\mathrm{W} / \mathrm{m}^{2} . A_{r}$ is snow-free ratio, which is defined as the ratio of equivalent snow-free area to total area. $A_{r}$ values of $0,0.5$ and 1 are normally used as the design conditions. $A_{r}=1$ represents the condition that the heat flux is sufficient to melt snow immediately so that there is no snow accumulation. $A_{r}=0.5$ represents the condition that all or a part of pavement is covered by a thin layer snow, which is equivalent to half of the pavement area is insulated by snow layer. $A_{r}=0$ represents the condition that all the pavement surface is covered by snow layer. The thickness of the snow layer is just adequate to prevent heat and evaporation losses, but the snow at the bottom of the layer melts at the same rate of snow accumulate. For most traffic conditions, snow melting rate that achieves $A_{r}=0.5$ is regarded as acceptable [27]. 


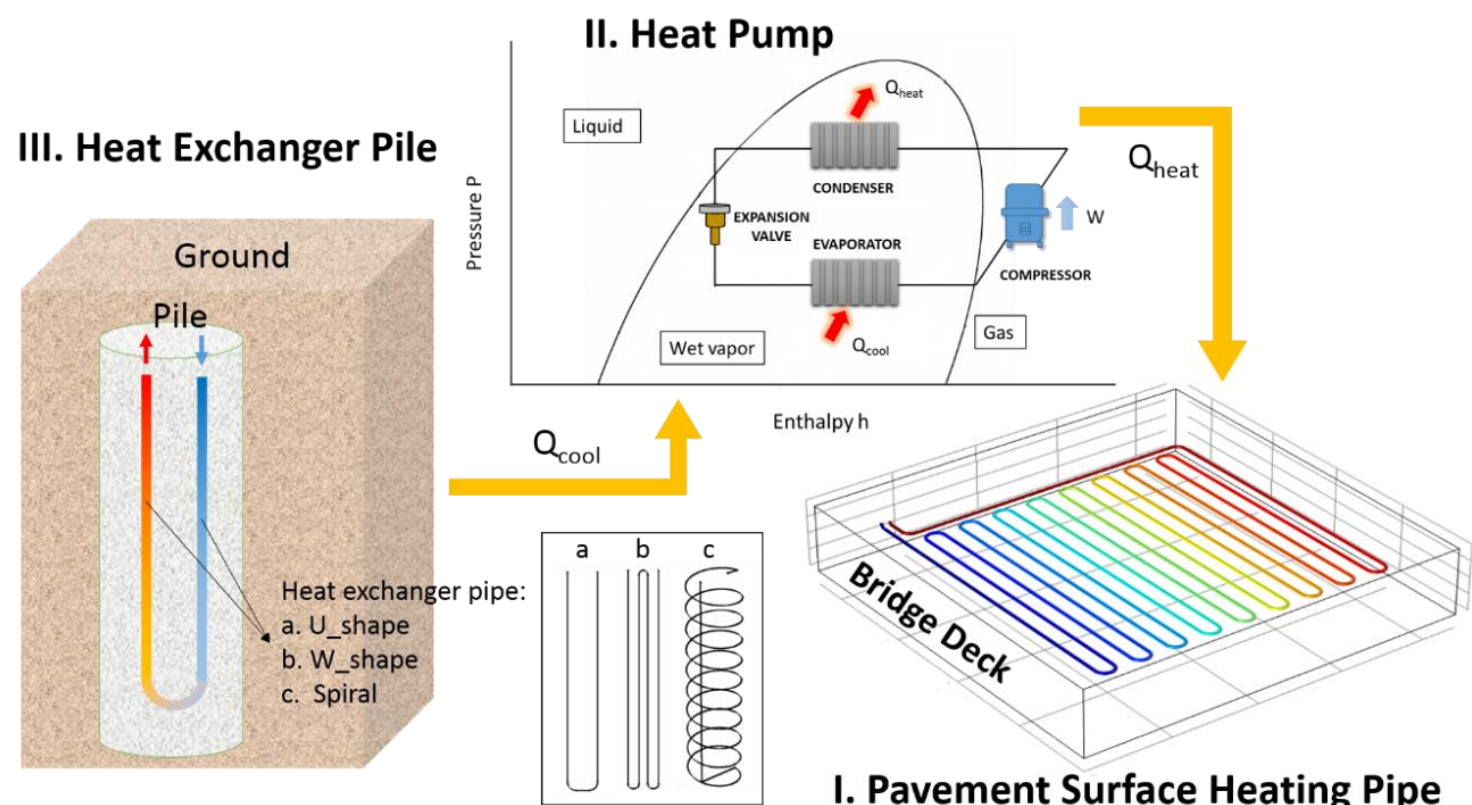

Fig. 2. Schematic diagrams of working principle of geothermal heat pump system

Based on the criteria described, the ASHRAE handbook (ASHRAE 2007) estimates the required heat fluxes for snow melting at 46 selected cities in U.S.. These include the heat fluxes satisfying different percentages of snow-melting loads at three different snow-free area ratios for each city [3].

This study assumes that the geothermal snow melting system is installed to heat a hypothetical bridge deck $200 \mathrm{~m}$ in length and $14.8 \mathrm{~m}$ in width (four lanes: $3.7 \mathrm{~m} \times 4$ ). Situations at 10 different selected cities are analyzed. The corresponding heat flux demands are calculated based on ASHRAE criteria and are listed in Table 1. The undisturbed ground temperature shown in this table is evaluated from Fig. 1(b). In principle, the most accurate undisturbed ground temperature can be derived from the results of geological survey; this however is impractical for every project due to high cost. An alternative way of applying groundwater temperature contour map is used, and this temperature yields the undisturbed ground temperature within $2^{\circ} \mathrm{C}$ [3]. The snowfall is assumed to be the average annual snowfall hours from 1982 to 1993 for each city [3]. The heat fluxes that achieve different reliabilities (90\%, 95\%, 99\% and 100\%) of snow melting area ratio are listed in Table 1. For example, Amarillo, TX (location 1), achieving snow melting area ratio $\mathrm{Ar}=1$ for $90 \%$ of times requires heat demand of $1397 \mathrm{~kW}$.

Table 1 Snow melting heat fluxes for the considered bridge deck at different design conditions

\begin{tabular}{|c|c|c|c|c|c|}
\hline No. & Location & $\begin{array}{l}\text { Undisturbed } \\
\text { Ground } \\
\text { Temperature }\end{array}$ & $\begin{array}{c}\text { Snowfal } \\
l\end{array}$ & $\begin{array}{l}\text { Snow-Free } \\
\text { Area Ratio }\end{array}$ & $\begin{array}{l}\text { Heat Demands to Achieve } \\
\text { Reliabilities based on Snowfall } \\
\text { Hours Data from } 1982 \text { through }\end{array}$ \\
\hline
\end{tabular}




\section{$1993, \mathrm{~kW}$}

\begin{tabular}{|c|c|c|c|c|c|c|c|c|}
\hline & & \multirow[b]{2}{*}{$\operatorname{deg} C$} & \multirow[b]{2}{*}{$\begin{array}{c}\text { hour/ye } \\
\text { ar }\end{array}$} & \multirow[b]{2}{*}{$\mathbf{A}_{\mathbf{r}}$} & \\
\hline & & & & & $90 \%$ & $95 \%$ & $99 \%$ & $100 \%$ \\
\hline \multirow{5}{*}{1} & & & & 1 & 1397 & 1572 & 2125 & 2972 \\
\hline & & & & 0.5 & 826 & 1006 & 1329 & 2850 \\
\hline & Amarillo, TX & 17 & 64 & 0 & 429 & 577 & 1074 & 2729 \\
\hline & & & & 1 & 1856 & 2158 & 2868 & 4458 \\
\hline & & & & 0.5 & 1000 & 1154 & 1539 & 2270 \\
\hline \multirow[t]{3}{*}{2} & Bismarck, ND & 9 & 158 & 0 & 281 & 361 & 681 & 1684 \\
\hline & & & & 1 & 1604 & 1880 & 2463 & 3306 \\
\hline & & & & 0.5 & 903 & 1039 & 1388 & 2688 \\
\hline \multirow[t]{3}{*}{3} & Cheyenne, WY & 8 & 224 & 0 & 349 & 488 & 938 & 2664 \\
\hline & & & & 1 & 1157 & 1462 & 2149 & 4034 \\
\hline & & & & 0.5 & 678 & 861 & 1376 & 2193 \\
\hline \multirow[t]{3}{*}{4} & Cleveland, $\mathrm{OH}$ & 13 & 188 & 0 & 349 & 441 & 855 & 2105 \\
\hline & & & & 1 & 1006 & 1151 & 1590 & 2173 \\
\hline & & & & 0.5 & 604 & 693 & 891 & 1841 \\
\hline \multirow[t]{3}{*}{5} & Lexington, KY & 17 & 50 & 0 & 281 & 361 & 512 & 1510 \\
\hline & & & & 1 & 1317 & 1604 & 1927 & 1986 \\
\hline & & & & 0.5 & 897 & 1074 & 1214 & 1465 \\
\hline \multirow[t]{3}{*}{6} & Memphis, TN & 18 & 13 & 0 & 696 & 710 & 909 & 1148 \\
\hline & & & & 1 & 1897 & 2347 & 3277 & 4496 \\
\hline & & & & 0.5 & 1033 & 1231 & 1711 & 2288 \\
\hline \multirow[t]{3}{*}{7} & Rapid City, SD & 10 & 177 & 0 & 281 & 358 & 604 & 1669 \\
\hline & & & & 1 & 672 & 829 & 1276 & 1788 \\
\hline & & & & 0.5 & 515 & 696 & 1074 & 1607 \\
\hline \multirow[t]{3}{*}{8} & Reno, NV & 16 & 63 & 0 & 423 & 636 & 1051 & 1486 \\
\hline & & & & 1 & 719 & 835 & 1122 & 1601 \\
\hline & Salt Lake City, & & & 0.5 & 580 & 1006 & 974 & 1601 \\
\hline \multirow[t]{3}{*}{9} & UT & 13 & 142 & 0 & 556 & 696 & 974 & 1601 \\
\hline & & & & 1 & 1524 & 1954 & 2664 & 3040 \\
\hline & & & & 0.5 & 894 & 1086 & 1424 & 1566 \\
\hline 10 & Wichita, KS & 16 & 60 & 0 & 423 & 530 & 770 & 1474 \\
\hline
\end{tabular}




\section{Heat pump}

Heat pump plays the role of energy carrier that transfers the harvested energy from the ground to the pavement. The refrigerant circulation in the heat pump is accomplished via four core components of Carnot cycle (Fig. 2), i.e., heat exchangers (evaporator and condenser), compressor, and expansion valve. During cold winter days, the thermal energy collected from energy piles (source load: $\mathrm{Q}_{\text {source}}$ ) is transferred to the evaporator and then disperses to the pavement via condenser (heating load: $\mathrm{Q}_{\text {heat }}$ ). The compressor and expansion valve implement the evaporation and condensing processes to achieve the complete refrigeration cycle. The performance of heat pump is typically indicated by its coefficient of performance (COP), which is defined as the ratio of heating load $\left(\mathrm{Q}_{\text {heat }}\right)$ to heat pump input work $(\mathrm{W})$ :

$C O P=\frac{Q_{\text {heat }}}{W}$. Since the heat load is the summation of source load and input work: $Q_{\text {heat }}=Q_{\text {source }}+W$, the source load for geothermal heat exchanger pile can be estimated by: $Q_{\text {source }}=\frac{C O P-1}{C O P} Q_{\text {heat }}$. The COP is the lump sum representation of the heat extraction per unit electricity consumption. The COP of heat pump is in the range of 3 to 5, which is based on experimental results [28], a conservertive value of $\mathrm{COP}=3$ is assumed to the analyses. The results of heat demand for snow removal of the bestbed bridge deck and the corresponding required thermal energy extraction are plotted in Fig. 3, assuming 99\% reliability. 

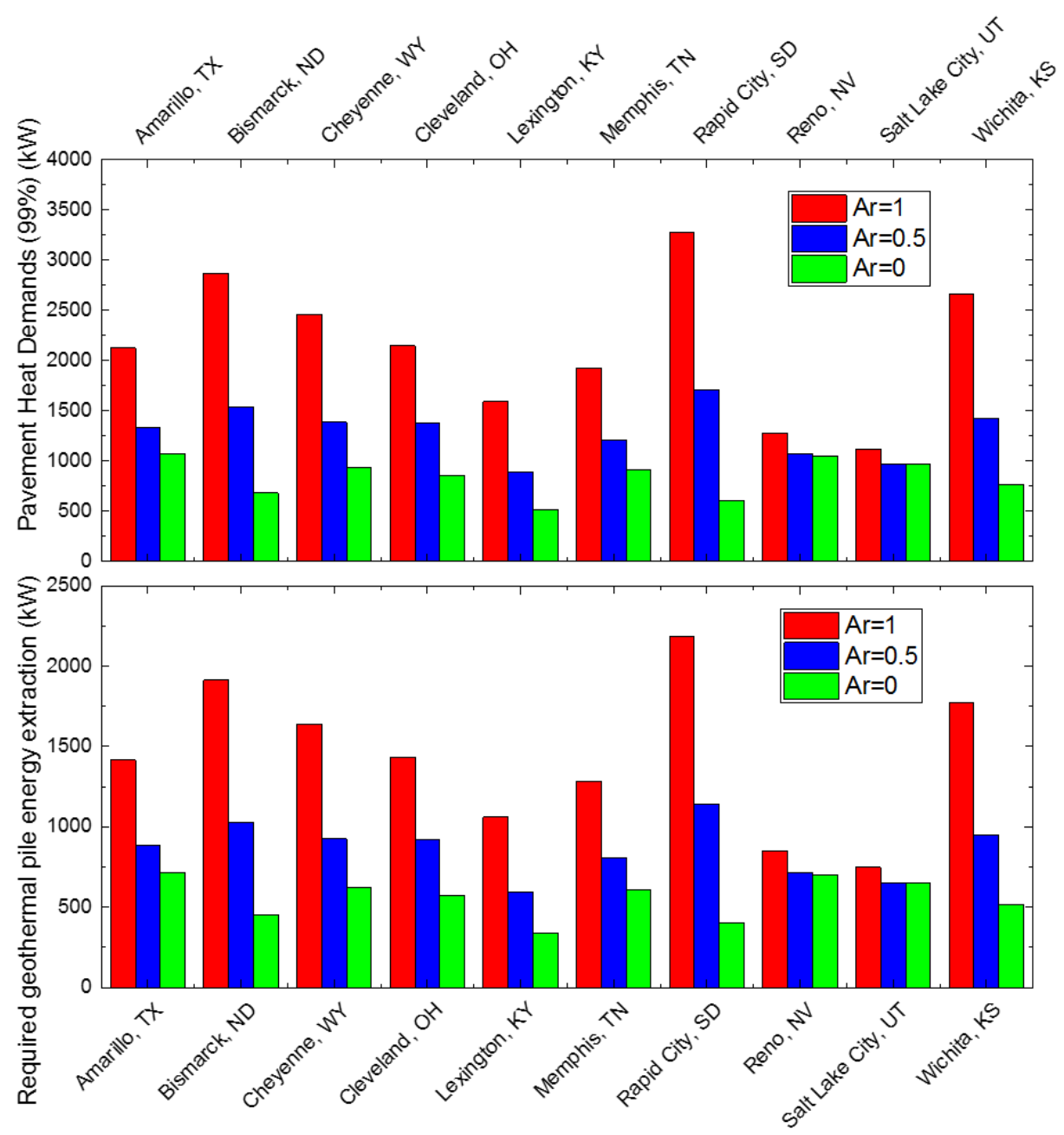

Fig. 3. Pavement heat demands and required geothermal pile energy extraction at different cities

\section{Geothermal heat exchanger pile}

Geothermal heat exchanger pile, which can serve as heat source for building Heating, Ventilating and Air-conditioning (HVAC) system, has drawn considerable attention because of their advantages of costeffectiveness and environment-friendliness. In order to estimate the energy extraction rate under different design conditions, a 3D finite element model is developed to analyze the performance of a single geothermal heat exchanger pile. The numerical simulation is implemented by coupling two different physics processes involved, i.e., non-isothermal pipe flow, which describes the heat transfer in the circulation fluid, and heat transfer, which describe the heat transfer between heat exchanger pile and ground. The governing equations for the numerical model are described as follows:

Non-isothermal pipe flow: 


$$
\left\{\begin{array}{l}
\frac{\partial A \rho_{w}}{\partial t}+\nabla \cdot\left(A \rho_{w} u\right)=0 \\
\rho_{w} \frac{\partial u}{\partial t}=-\nabla p-\frac{1}{2} f_{D} \frac{\rho_{w}}{d_{h}}|u| u+F \\
\rho_{w} A C_{p} \frac{\partial T}{\partial t}+\rho_{w} A C_{p} u \cdot \nabla T=\nabla \cdot(A k \nabla T)+\frac{1}{2} f_{D} \frac{\rho_{w} A}{d_{h}}|u| u^{2}+Q_{\text {wall }}
\end{array}\right.
$$

Heat transfer in the adjacent ground:

$$
\rho C_{p} u \cdot \nabla T=\nabla \cdot(k \nabla T)-Q_{\text {wall }}
$$

In Equations (2) and (3), $A$ is the cross section area of the pipe, $\mathrm{m}^{2} . \rho_{w}$ is the density of water, $\rho$ is the density of ground material, $\mathrm{kg} / \mathrm{m}^{3} . u$ is the fluid velocity, $\mathrm{m} / \mathrm{s} . \quad p$ is the pressure, $\mathrm{N} / \mathrm{m}^{2} . F$ is the volume force, including gravity, $\mathrm{N} / \mathrm{m}^{3} . C_{p}$ is the heat capacity at constant pressure, $\mathrm{J} /(\mathrm{kg} \cdot \mathrm{K}) . T$ is the temperature, K. $k$ is the thermal conductivity, $\mathrm{W} /(\mathrm{m} \cdot \mathrm{K}) . Q_{\text {wall }}$ is a source/sink term due to heat exchange with the surroundings through the pipe wall, W/m. This terms links the heat transfer processes in the pipe flow and ground.

Equation (2) describes the heat transfer in the circulation fluid, which includes conduction, convection, and dissipation, as well as the heat transfer between circulation fluid and the pipe wall (via the source/sink term $Q_{\text {wall }}$ ). Equation (3) describes the heat exchange between pipe wall and its surroundings ground, which is assumed to be solid materials. The heat exchange due to underground water flow, which is related to the complex hydrogeological conditions, is not considered in this analysis model. The heat transfer in the circulation fluid and adjacent ground is linked with boundary conditions that describe heat transfer processes between non-isothermal pipe flow, the pipe wall, and its surrounding ground.

For the heat transfer process in the non-isothermal pipe flow, the heat exchanger pipe is assumed to be High-density Polyethylene (HDPE) pipe with an inner diameter of $30 \mathrm{~mm}$ and a wall thickness of $2 \mathrm{~mm}$. The pipe flow is simplified as a one-dimensional flow, which neglects the heat exchange process in the radial direction inside the pipe. The advantage of this approach from computational aspect is to avoid the problem with meshing the pipe which is due to very large length to radius ratio. Churchill friction model is applied for thermal dissipation of the pipe flow in the longitudinal direction, and details of this model could be found in [29]. The inlet temperature is assumed to be $-4{ }^{\circ} \mathrm{C}$, which assembly enhances the system performance by maintaining relative large differential temperature between the ground and fluid while prevents the fluid from being too close to freezing temperature (can be $-20^{\circ} \mathrm{C}$ or lower for common 
types of circulation fluid with antifreeze chemicals). The geometry parameters and material properties of the heat exchanger pile [29] are listed in Table 2.

The computational domain for the adjacent ground is set to be a cylinder with $12 \mathrm{~m}$ diameter, and the diameter of the borehole and drilled shaft is set to be $1.2 \mathrm{~m}$ (Fig. 4(a)). Simplifications were made in the study to assume the ground thermal properties are constant. The thermal properties of the ground vary with depth and time can be measured with in-situ experiments, such dataset however is not widely available. This study aims to describe an effective approach to evaluate the feasibility of geothermal heat exchanger pile-based snow melting system for different regions in the United States. It builds a framework to conduct a project level feasibility analyses of GHE based snow removal system. When a more detailed analyses are needed for a particular site, the model and analyses method can be refined by applying in-situ measured data.

The Dirichlet boundary condition is applied on the borders of the computational domain (Fig. 4(b)) with the magnitude set to be the undisturbed ground temperature. The variation of ground temperature with depth is assumed to be a function of depth and time [31]:

$$
T(z, \mathrm{t})=\mathrm{T}_{m}+T_{a} e^{-z \sqrt{\frac{\omega}{2 a_{s}}}} \cos \left[\omega\left(\mathrm{t}-\mathrm{t}_{0}\right)-\mathrm{z} \sqrt{\frac{\omega}{2 a_{s}}}\right]
$$

where, $T_{m}$ is the average ambient temperature at the ground surface, $T_{a}$ is the amplitude of temperature variation at the ground surface, $\omega$ is the angular frequency of temperature variations, which is set as $2 \pi / 365 \mathrm{~d}-1, a_{s}$ is the solid thermal diffusivity, $\mathrm{t}_{0}$ denotes to the time (in days) when the maximum surface temperature occurs.

In this study, 10 cities were selected to represent the variety of climatic regions of United States, and for each location, the parameters of $T_{m}, T_{a}, \mathrm{a}_{\mathrm{s}}$ and $\mathrm{t}_{0}$ vary from each other considering the very different geological conditions and local weather conditions.

The physics-controlled mesh is adopted to generate the tetrahedral elements with the mesh refined near the GHE pipe to ensure the simulation accuracy (Fig.4(a)). 
(a)

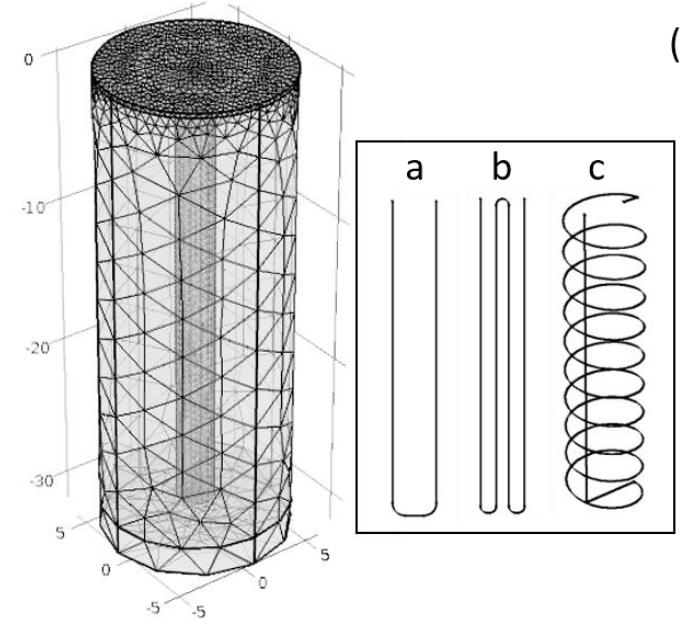

(b)

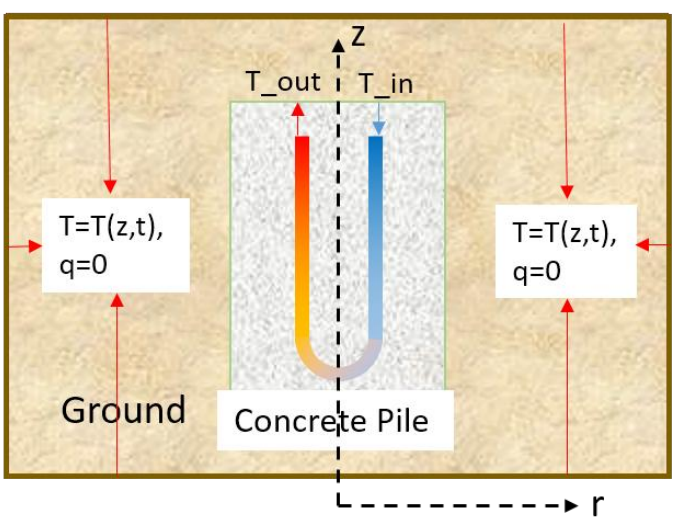

Fig. 4. (a) Finite element model of geothermal heat exchanger pile; (b) Schematic of boundary conditions

Table 2 Geothermal heat exchanger piles parameters [29]

\begin{tabular}{ll}
\hline Parameters & Description \\
\hline Geothermal heat exchanger pipe arrangement & Single U-shape, W-shape, Spiral \\
types & \\
Pile depth & $30 \mathrm{~m}$ \\
Pipe material & HDPE \\
Borehole backfilling & Concrete \\
Ground properties & Soil \\
Fluid inlet temperature & $-4^{\circ} \mathrm{C}$ \\
Fluid in the pipe & Water $+10 \%$ ethyl alcohol \\
Fluid flow rate & $0.3 \mathrm{~m} / \mathrm{s}-0.7 \mathrm{~m} / \mathrm{s}$ \\
Concrete thermal conductivity & $1.65 \mathrm{~W} / \mathrm{m} / \mathrm{K}$ \\
Concrete specific heat capacity & $837 \mathrm{~J} / \mathrm{kg} / \mathrm{K}$ \\
Ground thermal conductivity & $2 \mathrm{~W} / \mathrm{m} / \mathrm{K}$ \\
Ground specific heat capacity & $1000 \mathrm{~J} / \mathrm{kg} / \mathrm{K}$ \\
Water thermal conductivity & $0.56 \mathrm{~W} / \mathrm{m} / \mathrm{K}$ \\
Water specific heat capacity & $4190 \mathrm{~J} / \mathrm{kg} / \mathrm{K}$ \\
Pipe wall (HDPE) thermal conductivity & $0.46 \mathrm{~W} / \mathrm{m} / \mathrm{K}$ \\
Mesh sequence type & Physics-controlled mesh \\
\hline
\end{tabular}

\section{RESULTS AND DISCUSSIONS}


Sensitivity study is conducted by applying the geothermal heat exchanger pile model to assess the extracted energy rate under fluid velocity of $0.3 \mathrm{~m} / \mathrm{s}$ to $0.7 \mathrm{~m} / \mathrm{s}$ with typical undisturbed ground temperature ranging from $8^{\circ} \mathrm{C}$ to $18^{\circ} \mathrm{C}$. Besides, the performance of heat exchanger pile with three different heat exchange pipe arrangement (noted as type a, b and c in Fig. 2 and Fig. 4(a)) are evaluated. With the predicted geothermal heat exchanger pile performance, the design goal of snow removal at $99 \%$ and area ratio $\mathrm{Ar}=0,0.5$ and 1 are used as the target design conditions. From this, the required numbers of piles are determined, which is used as the feasibility criteria of geothermal heat exchanger pile-based bridge deck snow melting system for different cities, i.e., if an unrealistically large number of heat exchanger piles are needed to achieve the design goal in snow removal, it then is regarded as infeasible.

\section{Determination of energy extraction rate}

The computational model described is implemented to estimate the energy extraction rate. The model has been validated and calibrated with data from in-service ground heat exchange pipe [29-30]. This validated model is used to estimate the energy extraction rate under different working conditions. The influence of initial inlet temperature of circulation fluid is analyzed. The results show that the outlet temperature (which determines the amount of heat extraction from ground) after about 15 minutes of service is not affected by the initial temperature at the inlet (Fig. 5). It is primarily decided by the ground temperature conditions.

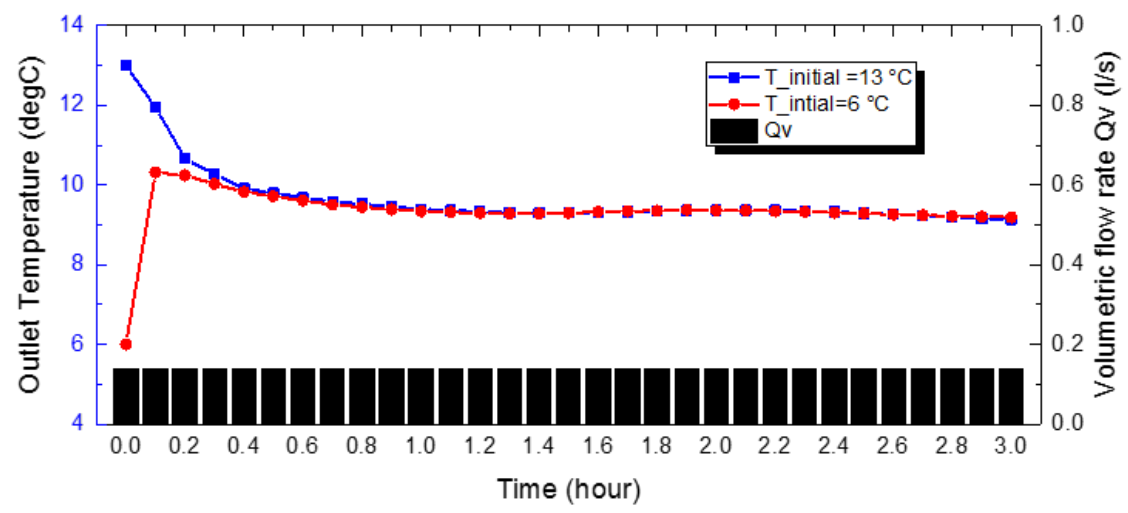

Fig. 5. Time process of simulated outlet temperature with different initial inlet temperatures

The geothermal snow system only runs during specific weather condition, or it typically operates under transient conditions. Therefore, the outlet temperature via transient model is used to calculate the energy extraction rate. Accordingly, Fig. 6 plots the outlet temperature versus ground temperature and its corresponding extracted energy for three common types of heat exchange pipe arrangement (noted as Types a, b and c respectively) at flow velocity of $0.3 \mathrm{~m} / \mathrm{s}$. The results show that higher ground temperature leads to more energy extraction, which is consistent with expectation. Pipe arranged in spiral 
shape (type c) extracts the largest amount of energy, which is around 2 and 3 times than that of W-shape (type b) and U-shape (type a), respectively. Thus, type c (pipe arranged in spiral shape) appear to be the best option for the geothermal pile based snow melting system under the constraints of limited pile length.
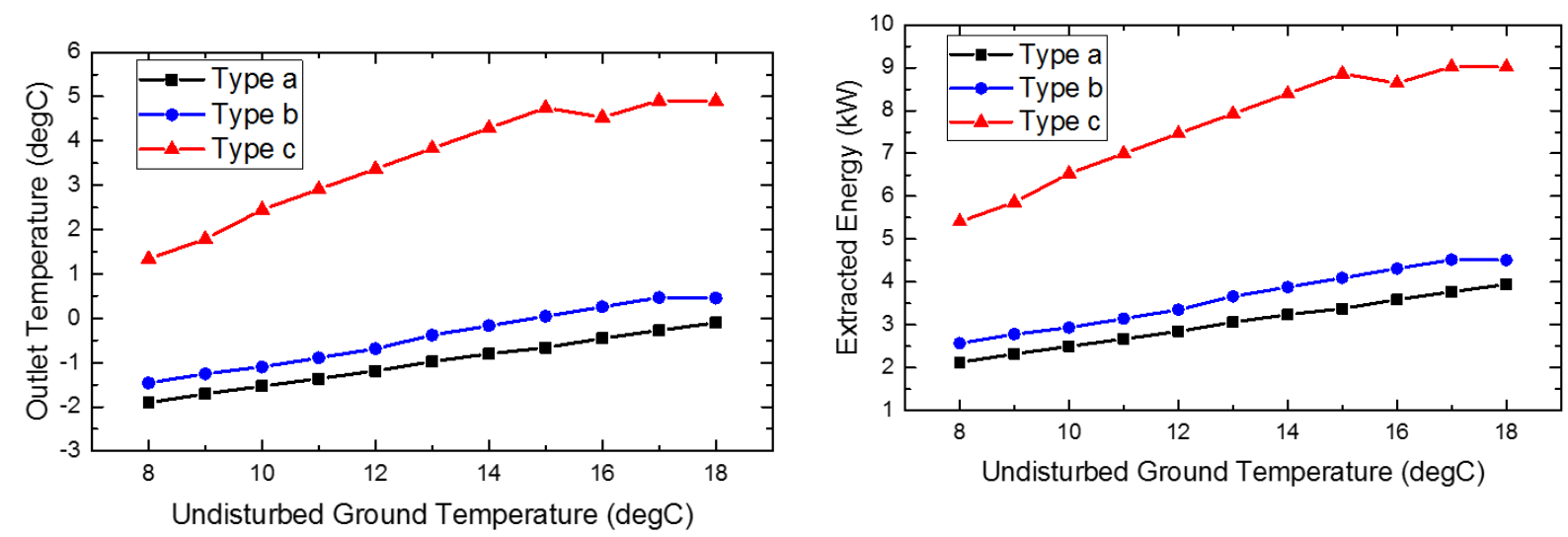

Fig. 6. Simulated outlet temperature and the corresponding extracted energy

\section{Operational parameters of geothermal heat exchanger with different pipe arrangement types}

Geothermal heat exchanger pile is a complex system, which might be influenced by many factors, i.e., pile length, fluid velocity, geological conditions, pipe arrangement, etc. The operational parameters need to be set to achieve the best performance. However, with the pile length determined primarily from load support considerations, the geometry (size and length) as well as materials for pile are determined primarily from the existing engineering practice. There are, therefore, two primary influencing factors that determine the geothermal extraction, i.e., type of pipe arrangement and velocity of circulation fluid. Sensitivity studies are conducted with the computational model, with focusing on the influence of types of heat exchanger pipe arrangement and the velocity of circulation fluid. The ground temperature in the range of $8^{\circ} \mathrm{C}$ to $18^{\circ} \mathrm{C}$ is also analyzed, which covers the range of ground temperature by the 10 selected cities. The results are summarized in Fig. 7, in terms of outlet temperature of circulation fluid and extracted thermal energy. The results show that there is no obvious change in the extracted energy by type a and type $b$ heat exchanger pipe when fluid velocity varies from $0.3 \mathrm{~m} / \mathrm{s}$ to $0.7 \mathrm{~m} / \mathrm{s}$. This, however, increases the extracted energy for type c, which is increased by around $20 \%$. Considering that higher circulation fluid velocity will result in more electrical energy consumption, the trade-off between the increases in the harvest energy and electricity consumption need to be further investigated. It is also seen that when the ground temperature increases from $8^{\circ} \mathrm{C}$ to $18^{\circ} \mathrm{C}$, there are increases in the extracted thermal energy by $84 \%, 81 \%$ and $83 \%$ for thermal exchanger pile with type a, type b and type c heat exchanger 
pipes, respectively. This provides an important evidence in that the ground temperature or location significantly affects the system performance.

(a)
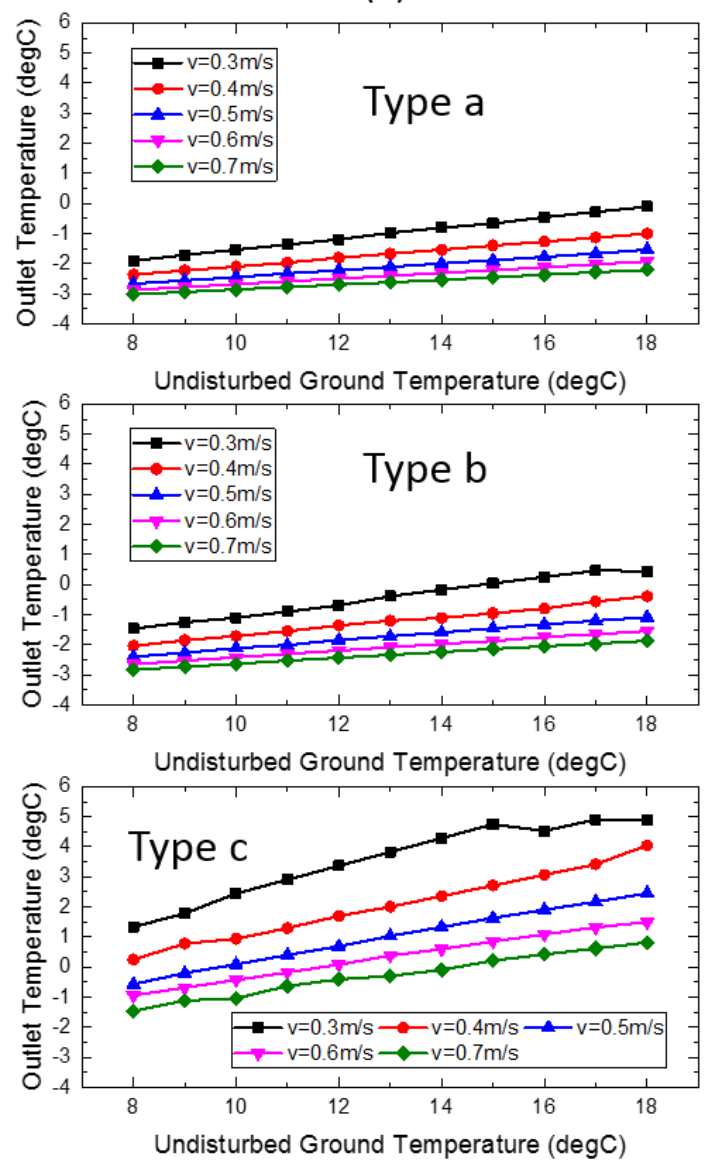

(b)
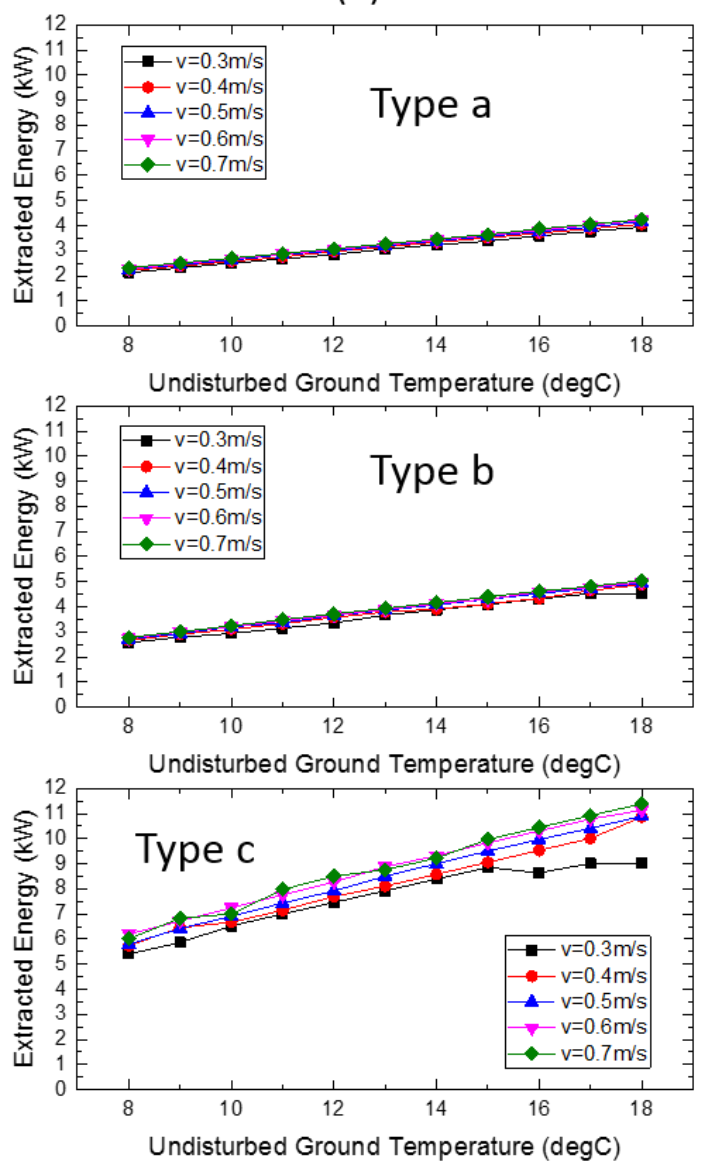

Fig. 7. Sensitivity analysis on pipe arrangement type and fluid velocity under different undistributed ground temperature

\section{Determination of required pile number}

With the amount of extracted thermal energy from a single heat exchanger pile installed with different types of heat exchanger pipes, the number of heat exchanger pile required for snow removal of the testbed bridge deck is estimated. The required number of pile number for the selected 10 cities at different design conditions is calculated by:

$$
N=Q_{\text {source }} / q
$$


where $Q_{\text {source }}$ is the required energy extraction for deck snow removal as obtained from Fig. 3, q is the energy extraction per single pile, which can be obtained from Fig. 7(b).

It needs to point out that factors such as the heat loss during the energy transferring process are ignored in the calculation of the required number of piles. Besides, factors such as pile and heat exchanger pipe design (i.e., variations in the pile diameter, pipe diameter, geological conditions, etc.) are not considered in details. However, since the objective of this study is to provide a gross estimation to evaluate the feasibility of geothermal heat exchanger pile based snow melting system at different locations, such simplifications are not expected to significantly affect the conclusions.

In order to characterize the cities' weather condition, a criterion is used to categorize the selected cities into four regions: I, II, III and IV on the basis of the undisturbed underground temperature and snowfall (Fig. 8).

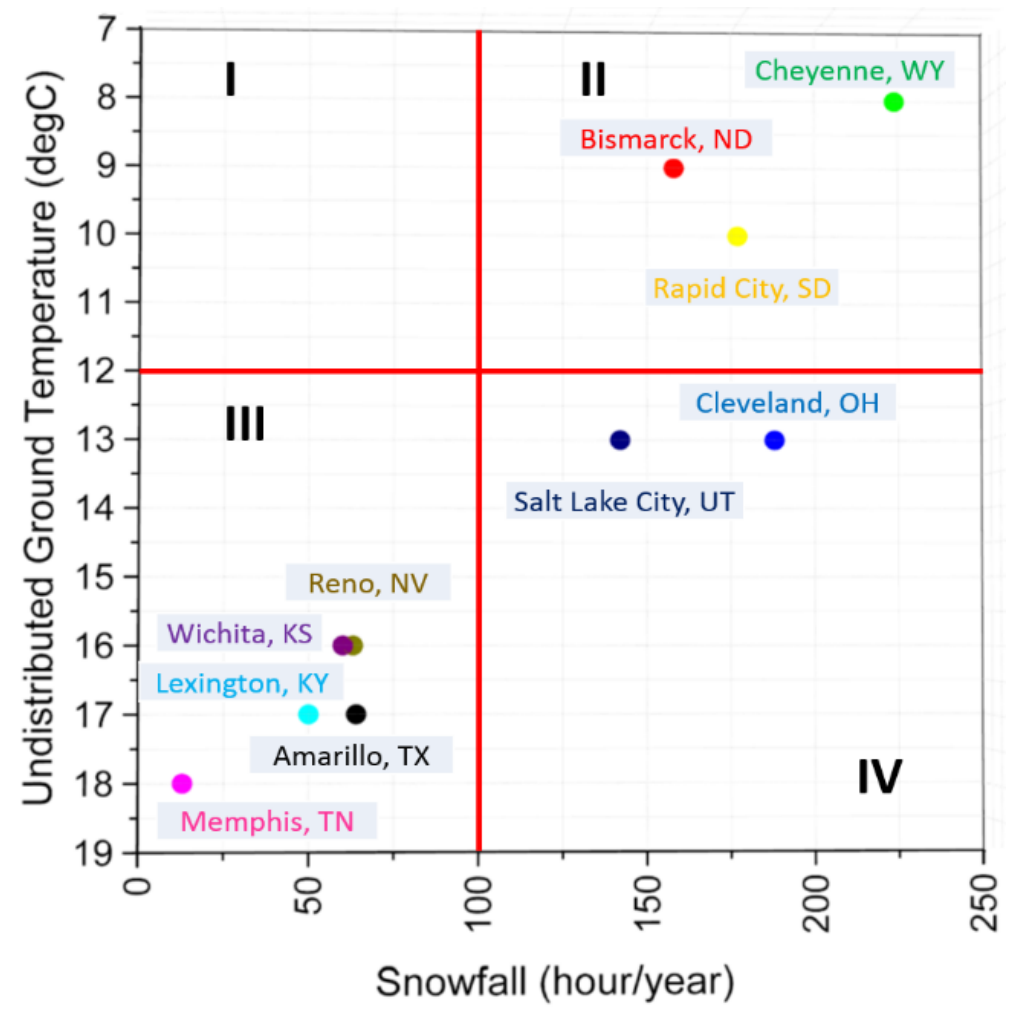

Fig. 8. Region classification for the selected 10 cities

The results of required number of thermal exchanger piles to achieve different extent of snow removal are summarized in Fig. 9. According to Fig. 9, generally, geothermal exchanger pile with type c exchanger requires the least number of pile, followed by type $b$ and type $a$. The design area ratio Ar of snow removal also significantly affects the required pile number, as compared with flow velocity. For 
each design snow removal condition, the required number of piles varies significantly depending on the particular location of the city. It can be observed that the cities located in region II suffer heavier snowfall and lower ground temperature, consequently, much more piles are required to satisfy the pavement snow melting demands, especially for $\mathrm{Ar}=1$ and $\mathrm{Ar}=0.5$. Meanwhile, due to the higher ground temperature and smaller amount of snowfall, the required pile number for the cities located in region III are significantly smaller compared with those in region II. The cities located in region IV require similar pile number as the cities located in region III. Overall, regardless of types of heat exchanger pile pipe arrangement, cities located in region II seem the least suitable for the application of geothermal heat exchanger pile based snow melting system, as indicated by the relative larger number of piles required for this region.

The number of piles required for a particular project is decided by the requirement to support the structural loads. As an example, by use 100 piles as the feasibility criteria for a four lane bridge deck $200 \mathrm{~m}$ in length, a few observations can be made based on this criterion.

As shown in Fig. 9, at the design condition of snow removal area ratio of $\mathrm{Ar}=0$, the required number of piles are below 100 for all the 10 cities except Cheyenne. For snow removal design condition of Ar=0.5, all the cities located in region III with flow velocity of $0.7 \mathrm{~m} / \mathrm{s}$ require less than 100 piles, except Wichita. At Ar=1 design condition, only Reno and Salt Lake City meet the requirement of less than 100 piles; they are therefore the most promising areas where the thermal heat exchanger pile is applicable and economic. While the criteria proposed is based on simplistic assumptions, it provides a quick way to assess the technical and economic feasibility of installing heat exchanger pipe to pile foundation to achieve different extent of snow removal. The overall observation is that the feasibility of geothermal heat exchanger pile is dependent upon the geological and snow conditions of a particular region, as well as the performance criteria. 

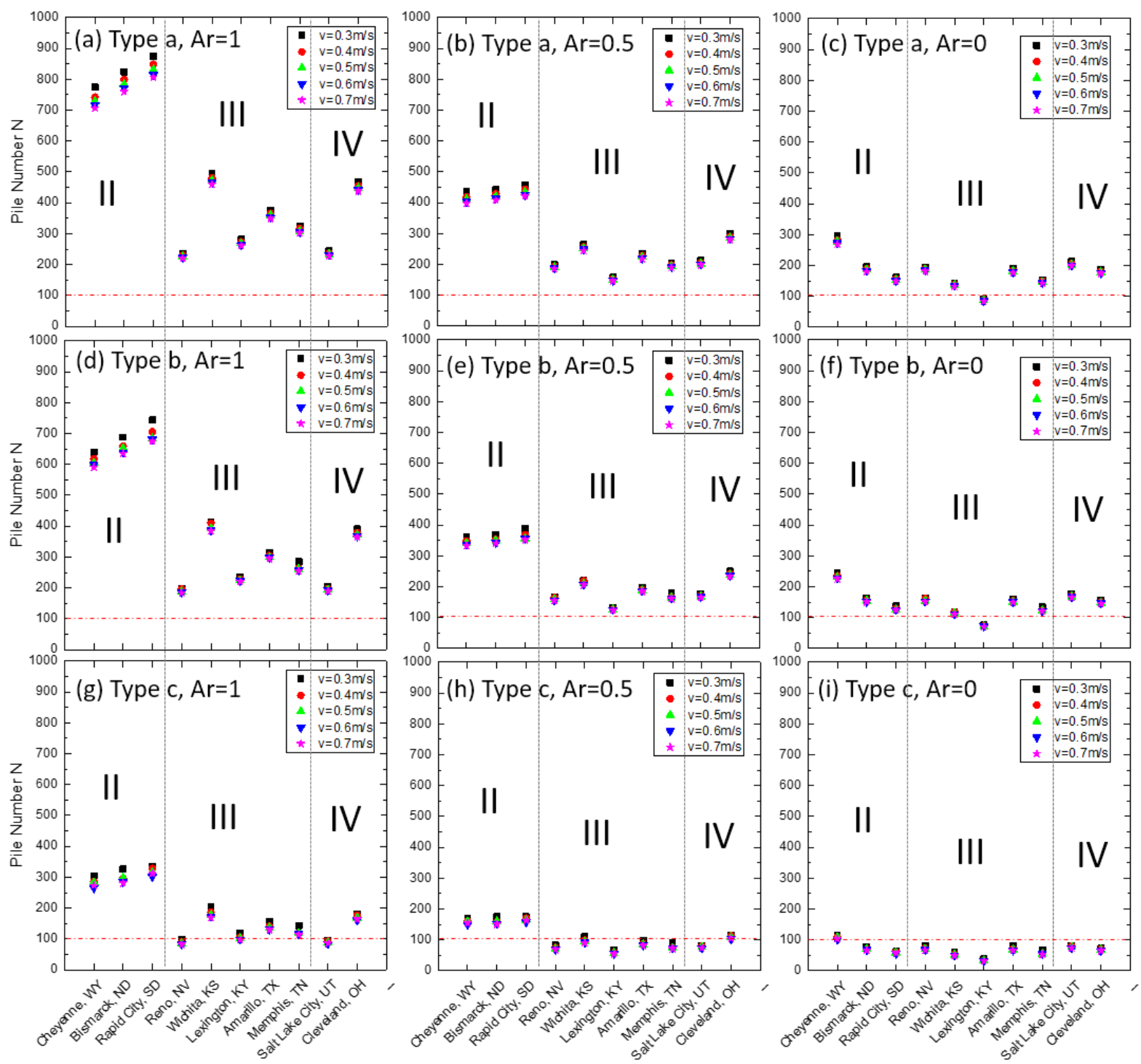

Fig. 9. Required pile numbers for the considered bridge deck located in selected ten cities under different design conditions

Table 3 summarizes the ratio of pavement heating area to total pile length from a few well documented projects, which typically ranges from 0.1 to 0.6 . Since these previous projects mostly used the U-shape arranged heat exchanger pipe (similar as type a in this analyses), for comparison purpose, the ratios of bridge deck heating area to the total pile length for type a heat exchanger pipe at different Ar values from this study are plotted in Fig. 10. The values of bridge deck heating area to the total length of pile lie in 0.1 to 0.5 when $\mathrm{Ar}=1$, which are consistent with these reported field projects. This provides certain validation of the results of this analyses. 
Table 3 Ratios of pavement heating area to total pile length for the reported projects

\begin{tabular}{cccccc}
\hline Project & Location & $\begin{array}{c}\text { Heating area } \\
\left(\mathrm{m}^{2}\right)\end{array}$ & $\begin{array}{c}\text { Borehole } \\
\text { depth }(\mathrm{m})\end{array}$ & $\begin{array}{c}\text { Borehole } \\
\text { number }\end{array}$ & Ratio \\
\hline SERSO [5, 11] & Switzerland & 1300 & 65 & 91 & 0.2 \\
Gaia snow melting system [9] & Japan & 266 & 150 & 3 & 0.59 \\
I-40 bridge deck de-icing system [15] & U.S. & 2556 & 76 & 250 & 0.13 \\
\hline
\end{tabular}

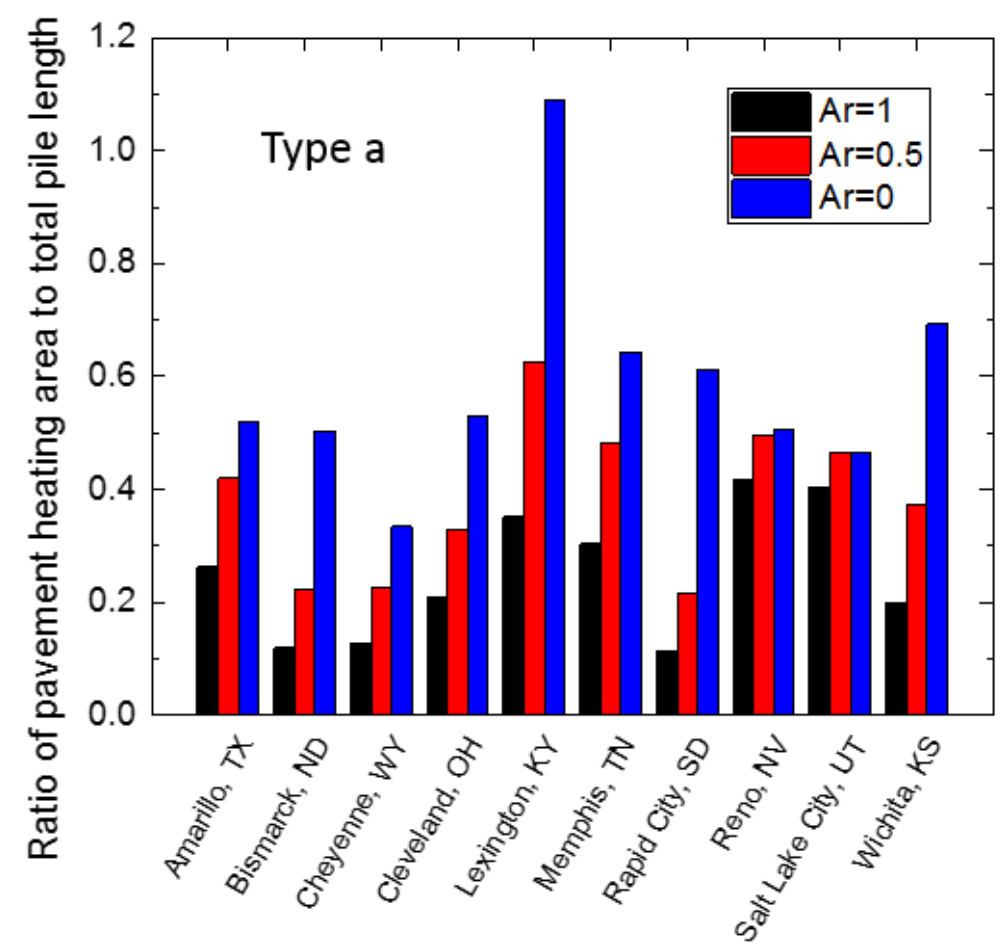

Fig. 10. Ratio of pavement surface area to total pile length for thermal exchanger pile with Type a heat exchange pipe

\section{CONCLUSIONS}

This paper describes a method to evaluate the feasibility of geothermal heat exchanger pile-based snow melting system for different regions in the United States. The method includes the overall energy demand analyses for bridge deck snow removal based on ASHRAE criteria. This is combined with the COP of typical geothermal heat exchange system to estimate the total demand on ground thermal energy extraction. A validated computational model is used to analyze the amount of thermal energy extraction by a single thermal energy exchanger pile installed with different types of heat exchanger pipes. From these, the number of thermal energy exchanger piles are determined. The method is applied to analyze 
the number of piles required for snow removal of bridge deck in 10 cities located in different U.S. states with different climatic conditions.

Major observations on the heat exchanger pile design and operations include, 1) spiral shaped heat exchanger pipe provides the highest performance in thermal energy extraction; 2) Increasing of circulation fluid velocity does not significantly benefit the energy extraction when using U-shaped (type a) or W-shaped (type b) heart exchange pipe. It, however, has a major influence on spiral shaped (type c) heat exchanger pipe.

The analyses of this paper indicate that there are promise to use heat exchanger piles for snow removal for regions with high ground temperature (such as region III and IV as classified in this study). Regardless of types of heat exchanger pile pipe arrangement, cities located in region II (which features low ground temperature and large snow fall) seem the least suitable for the application of geothermal heat exchanger pile based snow melting system, as indicated by the relative larger number of piles required for this region.

Overall, this paper provides a relatively simple framework that combines overall energy analyses and computational model to estimate the technical and economic viability of geothermal heat exchanger pile based snow melting system for bridge deck. These results show that the performance of geothermal heat exchanger pile based snow melting system is dependent upon the geological and snow conditions of a particular region, as well as the design snow removal criteria (real time versus non real time). By reducing the separate cost of drilling and installation as with conventional geothermal ground heat exchanger, the technical feasibility, however, needs to be determined based on the characteristics of underground thermal conditions and snow conditions. This paper uses the criteria of number of piles required as a simple feasibility criterion. The cost and benefits of geothermal heat exchanger piles in terms of life cycle cost benefits still need to be further analyzed.

\section{Acknowledgement}

This research is partially supported by the US National Science Foundation via grant No. 1131295 and China Scholarship Council.

\section{REFERENCE}

[1] Federal Highway Administration. Road Weather Management Program. http://www.ops.fhwa.dot.gov/weather/q1_roadimpact.htm.

[2] Federal Highway Administration, "Highway Statistics Publications, Highway Finance Tables SF4C and LGF-2, 1997-2005." 
[3] ASHRAE, ASHRAE Handbook: 2007 HVAC Applications: American Society of Heating, Refrigerating and Air-Conditioning Engineers, Inc., Atlanta, GA 30329, 2007.

[4] L. D. Minsk, "Heated Bridge Technology," U.S. Department of Transportation, Report on ISTEA. $7 / / 1999$.

[5] M. RAUBER, "Energy from Road Surfaces.," CADDET Renewable Energy Newsletter pp. 25-27, 1995.

[6] W. J. Eugster, "SERSO PLUS-Neue Wege in der Belagsheizung, GtE Nr. 38-39/2002," Mitteilungsblatt der Geothermischen Vereinigung e.V., vol. 38, pp. 10-14, 2002.

[7] I. Yoshitake, N. Yasumura, M. Syobuzako, and A. Scanlon, "Pipe Heating System with Underground Water Tank for Snow Thawing and Ice Prevention on Roads and Bridge Decks," Journal of Cold Regions Engineering, vol. 25, pp. 71-86, 2011.

[8] K. Morita and M. Tago, "Snow-Melting on Sidewalks with Ground-Coupled Heat Pumps in a Heavy Snowfall City," in World Geothermal Congress, Antalya, Turkey, 2005.

[9] K. Morita and M. Tago, "Operational Characteristics of the Gaia Snow-melting System in Ninohe, Iwate, Japan," in World Geothermal Congress, Kyushu-Tohoku, Japan, 2000.

[10] N. Nagai, S. Miyamoto, T. Tsuda, and S. Yamahata, "Experimental Demonstrations and Optimal Design Conditions of Snow-Melting System Using Geothermal and Solar Energy," in ASME 2009 Heat Transfer Summer Conference collocated with the InterPACK09 and 3rd Energy Sustainability conferences, San Francisco, 2009, pp. 767-771.

[11] W. J. Eugster, "Road and Bridge Heating Using Geothermal Energy. Overview and Examples," presented at the Proceedings European Geothermal Congress 2007, Unterhaching, Germany, 2007.

[12] K. Zwarycz, "Snow Melting and Heating Systems Based on Geothermal Heat Pumps at Goleniow airport, Poland," The United Nations University.11/21/ 2002.

[13] S. Li and X. Ye, "Study on the Bridge Surface Deicing System in Yuebei Section of Jingzhu Highway," International Journal of Business and Management, vol. 3, pp. 116-121, 2008.

[14] Y. Seo, U. Seo, J. Eum, and S.-J. Lee, "Development of a Geothermal Snow Melting System for Highway Overlays and Its Performance Validations," Hournal of Testing and Evaluation, vol. 39, pp. 592-602, 2011.

[15] J. D. Spitler, M. Ramamoorthy ., "Bridge Deck Deicing using Geothermal Heat Pumps. ," in Proceedings of the Fourth International Heat Pumps in Cold Climates Conference, Aylmer, Québec., 2000.

[16] X. Liu, S. J. Rees, and J. D. Spitler, "Modeling snow melting on heated pavement surfaces. Part II: Experimental validation," Applied Thermal Engineering, vol. 27, pp. 1125-1131, 4// 2007. 
[17] X. Liu, S. J. Rees, and J. D. Spitler, "Modeling snow melting on heated pavement surfaces. Part I: Model development," Applied Thermal Engineering, vol. 27, pp. 1115-1124, 4// 2007.

[18] J. D. S. Xiaobing Liu, "A Simulation Tool for the Hydronic Bridge Snow Melting System," presented at the 12th International Road Weather Conference, 2004.

[19] J. D. S. Simon J. Rees, Xia Xiao, "Transient Analysis of Snow-Melting System Performance," 2002.

[20] H. Xu and Y. Tan, "Development and Testing of Heat- and Mass-Coupled Model of Snow Melting for Hydronically Heated Pavement," Transportation Research Record: Journal of the Transportation Research Board, vol. 2282, pp. 14-21, 2012.

[21] H. Xu and Y. Tan, "Modeling and operation strategy of pavement snow melting systems utilizing low-temperature heating fluids," Energy, vol. 80, pp. 666-676, 2/1/ 2015.

[22] S. Miyamoto and M. Takeuchi, "Snow-melting system on road using seasonal energy storage through foundation piles for bridge," 2005, pp. 51-62.

[23] M. Takeuchi, K. T., S. Miyamoto, and T. Y., "Development and numerical simulation of snowmelting system using geothermal energy collected by building piles " Transactions of the Society of Heating, Air-Conditioning and Sanitary Engineers of Japan, pp. 59-69, 1993.

[24] G. Allen Bowers Jr. and C. G. Olgun, "Experimental Investigation of Bridge Deck Deicing Using Energy Piles," presented at the IFCEE 2015, San Antonio, 2015.

[25] F. Dupray, C. Li, and L. Laloui, "Heat-exchanger piles for the de-icing of bridges," Acta Geotechnica, vol. 9, pp. 413-423, 2014.

[26] W. P. Chapman and S. Katunich, "Heat Requirements of Snow Melting Systems," ASHRAE Transactions, vol. 62, p. 359, 1956.

[27] Williams, G.P. Heat Requirements of Snow Melting Systems in Canada. Proceedings of 1st National Conference on Snow and Ice Control, April 1973, Ottawa: Roads and Transportation Association of Canada, pp. 179-197.

[28] S. J. Self, B. V. Reddy, and M. A. Rosen, "Geothermal heat pump systems: Status review and comparison with other heating options," Applied Energy, vol. 101, pp. 341-348, 1// 2013.

[29] C. Han and X. Yu, 2016a, "Sensitivity analysis of a vertical geothermal heat pump system," Applied Energy, vol. 170, pp. 148-160, 5/15/ 2016.

[30] C. Han and X. Yu, "Performance of a residential ground source heat pump system in sedimentary rock formation," Applied Energy, vol. 164, pp. 89-98, 2/15/ 2016.

[31] C. Doughty and A. Nir, Chin-Fu, Tsang. (1991). "Seasonal thermal energy storage in unsaturated soils: Model development and field validation”, Other Information: PBD: Jun 1991 (pp. Medium: ED; Size: 81 p.). 